\title{
Challenges and opportunities for improved understanding of regional climate dynamics
}

Article

Accepted Version

Collins, M., Minobe, S., Barreiro, M., Bordoni, S., Kaspi, Y., Kuwano-Yoshida, A., Keenlyside, N., Manzini, E., O'Reilly, C. H., Sutton, R., Xie, S.-P. and Zolina, O. (2018) Challenges and opportunities for improved understanding of regional climate dynamics. Nature Climate Change, 8. pp. 101-108. ISSN 1758678X doi: https://doi.org/10.1038/s41558-017-0059-8 Available at https://centaur.reading.ac.uk/76320/

It is advisable to refer to the publisher's version if you intend to cite from the work. See Guidance on citing.

To link to this article DOI: http://dx.doi.org/10.1038/s41558-017-0059-8

Publisher: Nature Publishing Group

All outputs in CentAUR are protected by Intellectual Property Rights law, including copyright law. Copyright and IPR is retained by the creators or other copyright holders. Terms and conditions for use of this material are defined in the End User Agreement. 


\section{CentAUR}

Central Archive at the University of Reading

Reading's research outputs online 


\section{Climate Dynamics and Regional Climate Change}

Matthew Collins* (1), Shoshiro Minobe (2), Marcelo Barreiro (3), Simona Bordoni (4), Yohai Kaspi (5), Akira Kumano-Yoshida, (6), Noel Keenlyside (7), Elisa Manzini (8), Chris O’Reilly (9), Rowan Sutton (10), Shang-Ping Xie (11), Olga Zolina (12)

1. University of Exeter, UK ( ${ }^{*}$ Corresponding Author)

2. Hokkaido University, Japan

3. Universidad de la República, Uruguay

4. California Institute of Technology, USA

5. Weizmann Institute of Science, Israel

6. Kyoto University, Japan

7. Geophysical Institute, University of Bergen and Bjerknes Centre for Climate Research, Norway

8. Max Planck Institute for Meteorology, Germany

9. Atmospheric Physics, University of Oxford, UK

10. NCAS Climate, University of Reading, UK

11. Scripps Institution of Oceanography, University of California San Diego, USA

12. L'Institut des Géosciences de l'Environnement, L'Université Grenoble Alpes, France and Shirshov Institute of Oceanology, RAS, Russia 


\section{Abstract}

Dynamical processes in the atmosphere and ocean are central in determining the large-scale drivers of regional climate change, yet predictive understanding of climate dynamics is poor. In this perspective article, we identify three frontline problems in climate dynamics, in which progress is possible, and which will lead to improved predictions and projections and more robust information for climate change adaptation. These problems involve (i) the response to external forcing of storms, blocks and jet streams, (ii) ocean-basin to ocean-basin and tropical-extratropical teleconnections and (iii) the development of predictive theories of climate dynamics involving non-linear interactions between the dynamics and physics of the atmosphere and ocean. We highlight opportunities and techniques for making immediate progress in climate dynamics, namely the development of high-resolution coupled model simulations, partial coupling or pacemaker experiments and the development and use of dynamical metrics and dynamical hierarchies of models. Our particular focus is on the role of the ocean in providing a slowly-evolving boundary condition, and its coupling and interaction with the atmosphere, that plays a central role in driving internal climate variability and in modulating forced climate change.

\subsection{Introduction}

The topic of 'Climate Dynamics' encapsulates the dynamical interaction of the atmosphere and ocean with each other as well as with other components of the Earth system, playing a leading-order role in regional climate, both in the response to external forcing and the background internal natural variability. As has been recognized for many decades, the role of the ocean and air-sea interaction is at the core of climate variability and change on seasonal to centennial time scales ${ }^{1}$.

Much research on climate dynamics has focused on statistical descriptions of variability and change. Empirical Orthogonal Function (EOF) analysis, or other techniques are used to define indices of 'modes' of variability, such as the North Atlantic Oscillation (NAO), the Pacific North American (PNA) pattern and the Southern and Northern Annular Modes (SAM/NAM). These descriptions offer compact ways of describing regional climate and its impacts but are less useful in providing insight into the dynamical and physical processes that drive variability and change. More importantly, they lack the ability to provide the basis for prediction beyond the use of emprical methods. We must advance from using simple 
descriptive indicators to quantitative theories that will lead to more reliable predictions and projections of climate to inform adaptation.

Variations in weather are controlled by large-scale dynamical processes in the atmosphere, for example, extratropical storms, blocking, jet streams, tropical waves coupled to atmospheric convection, shifts in tropical convergence zones and monsoon flows. On time scales of days to a week, many of these phenomena can be predicted using initialized numerical models and there is a basic understanding of the dynamical processes involved in their variations (e.g., storms are carried by westerly advection and the Rossby wave mechanism, and grow on horizontal temperature gradients). Weather forecasting up to the medium range is a relatively mature area of meteorology ${ }^{2}$.

On climate time scales, such as projections for the end of the century, we look to quantify the response of the climate system to external forcing (mainly increasing greenhouse gas concentrations), and measure this against the unpredictable background noise of natural internal climate variability. For more near-term or decadal predictions, it is both the forced response and the predictable component of the natural internal variability that is sought ${ }^{3}$. (We make the distinction here between projections that are conditioned on a particular scenario of future emissions or concentrations, and predictions that rely in initial conditions and where the scenario is less important.)

Both prediction and projection involve the understanding of dynamical motions of the fast-moving atmosphere, modulated by the slowly varying ocean, ice and land surface signals, or external factors, including both natural and anthropogenic forcing of climate. The ocean is a major player in climate dynamics - occupying seven tenths of the Earth's surface. It is the main source of atmospheric water vapour, with far greater capacity to store heat than the atmosphere, and is dynamically varying in terms of its circulation and water properties. We seek to understand, and predict and project statistical measures of the behaviour of dynamical phenomena, such as the average and variability of the position of the jet stream and Inter Tropical Convergence Zone (ITCZ), or the intensity and structural organization of storm tracks, and associated strength and frequency of storm events.

Here there is a dynamical 'gap' in our understanding. While we have conceptual models of how weather systems form and can predict their evolution over days to 
weeks, we do not have theories that can adequately explain the reasons for an extreme cold or warm, or wet or dry, winter at continental scales. More importantly, we do not have the ability to predict such states. Likewise, we can build and run complex models of the Earth System, but we do not have adequate tools for quantitatively understanding the predictions and projections they produce and for understanding why different models give different answers.

For example, much of the understanding we have gained on spatial patterns of climate change has resulted from adopting an energetic framework in which radiative forcing is separated from radiative feedbacks in the climate system ${ }^{4}$. This paradigm has led to progress in quantifying feedbacks associated with, for instance, surface albedo, water vapour and atmospheric lapse rate and clouds. Despite shifts to regional approaches ${ }^{5}$, it is difficult to account for changes in horizontal transports of energy associated with dynamical processes using this approach. We require new ways of thinking.

Climate dynamics has traditionally been developed in studies of interannual variability. The coupled ocean-atmospheric perspective laid the foundation of seasonal forecasts routinely issued today. However, notwithstanding the many challenges still faced by the seasonal forecasting community, our hypothesis is that climate dynamics is insufficiently applied in studies of near-term and regional anthropogenic climate change in favour of global mean warming, climate feedback, or other robust thermodynamic mechanisms. Atmospheric circulation change have been identified as the leading source of uncertainty in regional climate predictions on decadal time scales ${ }^{3}$ and projections on longer time scales ${ }^{6,7}$. The need to understand and reduce uncertainties in regional climate projections represents both a challenge and an opportunity to extend climate dynamics.

In this article we identify a number of challenges in climate dynamics and suggest ways in which progress may be made. While not an exhaustive list, we identify the challenges as priority areas of research for the climate dynamics community.

\subsection{Frontline Problems in Climate Dynamics}

\subsection{Response to External Forcing of Mid-latitude Jets, Storms and Blocking}


Assessment of the impact of forced climate change on midlatitude weather systems indicates low confidence in changes in future projections for the end of the century ${ }^{8}$. There is also limited success in transferring skill in predicting extra-tropical ocean heat content to continental regions ${ }^{3}$. Our ability to quantify the sensitivity of storm tracks to external factors such as greenhouse gas increase or natural fluctuations such as ocean heat content anomalies and their role in modifying surface heat exchange is limited by a lack of quantitative theory of how storm tracks respond to changing boundary conditions on seasonal time scales and beyond, and by large random internal variability of the atmosphere.

Many complex climate models are now only just reaching a stage in which storms and storm tracks are simulated in the present day with reasonable fidelity. The structure of Atlantic and European winter blocking is also now represented reasonably well by some models, albeit with slightly reduced frequency in comparison with observations ${ }^{9}$. Additionally, excessive precipitation associated with storms is often found over the ocean, leading to inadequate precipitation extremes over land ${ }^{10}$ - problem that may be alleviated by increasing model resolution ${ }^{11}$, see below.

Under climate change there are competing influences on $\mathrm{N}$. Hemisphere storms and blocking. Polar amplification and sea-ice loss would tend to weaken the low-level baroclinicity (the energy source for storms) and ocean circulation changes associated with western boundary currents may exert a regional influence on temperature gradients ${ }^{12}$. Warming of the atmosphere in the tropics and subtropics enhances mid-latitude baroclinicity at upper levels, whereas dynamical warming of the stratosphere due to the increase in the Brewer-Dobson circulation counteracts the enhancement of upper-level baroclinicity ${ }^{13-15}$. Vertical stability of the atmosphere is increased but latent heat release in storms is enhanced due to enhanced moisture content. The thermodynamic component of moisture transport may rise under climate change due to enhanced column water vapour, but the total transport may decrease if the dynamical transport declines enough ${ }^{16}$. Regional complications are also likely.

Models tend to show only modest changes in storm tracks in climate change scenarios in the N. Hemisphere, although a feature that is not fully understood is the extension of the Atlantic storm track over the UK and associated cyclones propagating into northern Europe ${ }^{17}$. Models generally project a reduction and eastward shift in blocking occurrence that appears to result from mean state changes 
${ }^{18}$. While thermodynamic aspects of storms and storm tracks in the N. Hemisphere seem relatively robust across models, there is little confidence in their projected changes in dynamical aspects ${ }^{19}$.

In the S. Hemisphere, a poleward shift of a few degrees latitude is observed as lowlevel baroclinicity intensifies with reduced surface warming over the Southern Ocean ${ }^{20}$, albeit with some uncertainty in observations and reanalyses. Models with equatorward biases in the latitude of the $\mathrm{S}$. Hemisphere westerlies simulate the largest poleward shift as a result of climate change ${ }^{21}$. However, polar ozone recovery may oppose changes induced by greenhouse gas increases in the near term.

The impact of reductions in Arctic sea ice on storm tracks and blocking has been a topic of considerable recent research ${ }^{22,23}$, revealing a lack of quantitative understanding of the contribution of sea-ice loss. Models that simulate larger Arctic amplification under climate change tend to depict equatorward shifts of the jet whereas the jet shifts poleward in those with smaller Arctic amplification ${ }^{24,25}$. Theories of how sea ice retreat might influence storms and blocking are incomplete ${ }^{26}$. One particular question is how an upstream perturbation to sea-ice and surface heat fluxes might influence a downstream storm development.

\subsection{Basin-to-Basin and Tropical-Extratropical Teleconnections}

Much research in climate dynamics has been focussed on understanding the dynamics of basin-scale modes of variability such as the EI Niño Southern Oscillation (ENSO), the Pacific Decadal Oscillation/Interdecadal Pacific Oscillation (PDO/IPO) and Atlantic Multi-decadal Variability (AMV). While these are far from solved problems, it becomes increasingly apparent that interactions between ocean basins and interactions between the tropics and the extratropics (including polar regions see above) can drive global-scale variability.

The global warming 'hiatus' provides an example of a climate event, potentially related to inter-basin teleconnections. While decadal climate variations are expected, the magnitude of the recent event was unforeseen. A decadal period of intensified trade winds in the Pacific and cooler SSTs has been identified as a leading candidate mechanism for the global slowdown in warming ${ }^{27-29}$. Forcing from a warm tropical Atlantic has been highlighted as a possible cause ${ }^{30-32}$, invoking feedbacks between 
SSTs and winds in the Pacific (Fig. 1). Other studies have noted interactions between the Pacific and the Indian Ocean as being important in sea-level variations ${ }^{33}$. This, of course, raises the issue of the cause of decadal and multi-decadal variability in remote ocean basins that teleconnect to the Pacific. In the Atlantic, the large-scale ocean overturning is a prime candidate, although there has been some debate in the literature about a potential role for aerosols and simple mixed-layer ocean dynamics ${ }^{34-37}$. Observational estimates of surface turbulent heat fluxes seem to indicate that the atmosphere is responding to SST anomalies on time scales longer than 10 years pointing to oceanic dynamical processes as the ultimate cause of the hiatus ${ }^{38}$. Other authors have noted the role of internally generated variability in the atmosphere ${ }^{39,40}$. It is not clear if models can capture the magnitude of AtlanticPacific connections as deduced from observations ${ }^{41}$.

Tropics to high-latitude teleconnections are also evident. The atmospheric circulation around Antarctica shows trends in the observations that are linked to a complicated pattern of re-organisation of sea ice, particularly around the minimum in Austral Spring. Some regions show increasing sea-ice concentration trends and some show decreases, linked to variations in local winds ${ }^{42}$. This is in stark contrast to the Arctic that displays a clear downward trend across the basin. The Antarctic trends have been linked to trends in tropical SST anomalies ${ }^{43,44}$ with a notable role for both the IPO and Atlantic anomalies. It is also suggested that a hemispheric teleconnection exists between AMV and Antarctic sea-ice trends ${ }^{45}$. In the Southern Hemisphere, large-scale extratropical forcing has been shown to influence the strength of the South Atlantic Convergence Zone ${ }^{46}$.

An outstanding problem in quantifying the forced climate response to anthropogenic greenhouse gases is determining the spatial pattern of north-south asymmetry in warming: the $\mathrm{N}$. Hemisphere warms more than the $\mathrm{S}$. Hemisphere in models ${ }^{47}$. A simple explanation, based on the greater $N$. Hemisphere landmass, is inadequate and it seems that the ability of the $S$. Ocean to more efficiently uptake heat is important ${ }^{48}$. Nevertheless, the $\mathrm{S}$. Ocean is a region of known biases in climate models, with SSTs being generally too warm as a result of too much incoming SW radiation reaching the surface ${ }^{49}$. The relative energy balance of the two hemispheres, and the related cross-equatorial energy transport, is gaining prominence as a key determinate of many large-scale dynamical features ${ }^{50}$. Subtle changes in heat transport may be manifest as quite large changes in, for instance, monsoon flows and associated rains ${ }^{50}$. 


\subsection{Developing Predictive Theories of Climate Dynamics}

Simple theoretical models have been instrumental in understanding, for example, the basic dynamics of the ENSO cycle ${ }^{51}$. These models have been extended to diagnose the behaviour of coupled climate models and may be regarded as 'processbased' ways of evaluating models. Concepts such as Quasi-Geostrophic theory or the Lorenz Energy Cycle have also been used in the past as advanced diagnostics for understanding the behaviour of models and the real world. 'Theories', or 'predictive theories', in this sense relate to robust aspects of the dynamics of simple models that can also be found in more complex models. This is closely related to prediction in the forecasting sense but may be subtly different in the case of climate change. An example would be quantitative predictions of the poleward extent of the Hadley Circulation at different levels of global warming.

The challenges in developing theories of regional climate change come in dealing with non-linear interactions between processes and diverse time scales from days to decades. One definition of climate is that it is the cumulative effects of weather, hence any theory must account for the feedbacks between weather events and their modulators such as variations in SST or ocean heat content. The number of processes and non-linear interactions that can be represented in conceptual models, which are formulated in terms of only a handful of differential equations, is clearly limited. We need to develop ways to derive predictive theories of climate dynamics that include the interactions between key dynamical and physical processes. As stated above, statistical descriptions such as EOFs provide compact ways of representing some aspects of the climate system but fall short in providing predictive theories ${ }^{52,53}$.

The midlatitude eddy-driven jets provide an example. They are sustained by nonlinear eddy momentum fluxes which are a consequence of the baroclinic instability of the jet itself. The eddy driven jet in both hemispheres varies in position and strength but there is currently no quantitative theory that can predict the magnitude of such variations. It remains a considerable challenge to advance our understanding of climate dynamics involving non-linear interactions across a range of space and time scales. 


\subsection{Making Progress: Techniques and Opportunities}

\subsection{High Resolution Coupled Modelling}

It is not obvious that continually increasing the resolution of climate models leads to more accurate predictions or projections of regional climate change, whatever the time scale. Better representation of features such as coastlines and mountains undoubtedly gives more regional information but it is the large-scale drivers of regional change, a simple example being a change in the direction of the prevailing wind, which are the leading-order sources of uncertainty. In increasing resolution, we look to 'unlock' physical processes that are missing from low-resolution models, including interactions across multiple spatial scales, and to significantly reduce biases in the simulated present-day climate.

It has now become clear that anomalous conditions in western extratropical ocean basins can affect the atmospheric circulation. The zero-order effect of extratropical oceans is that of increasing the persistence of atmospheric anomalies through reduced heat flux damping ${ }^{54}$. This process has shown to be important, for example, for increasing the predictability of surface temperature in Southeastern South America ${ }^{55}$. Moreover, recent studies have indicated that SST gradients and strong ocean-to-atmosphere heat and moisture fluxes associated with variations in western boundary currents (such as the Gulf Stream and Kuroshio) can have a significant local influence on atmospheric vertical velocities through sea-air energy exchanges, providing diabatic sources of heating and moistening of the troposphere (Fig. 2) ${ }^{56-58}$. A realistic Gulf Stream, accompanied by strong horizontal temperature gradient, is found to be important in producing realistic blocking and jet stream distribution in an atmospheric numerical model ${ }^{59,60}$. The mechanisms for this are likely to involve lower atmospheric meridional temperature gradients caused by strong SST gradients across the currents and/or latent heat release associated with the moisture supply from the currents ${ }^{61}$. Interactions between SST fronts, storms and storm tracks have been shown to impact storms in the Pacific ${ }^{62}$ and blocking events in the Atlantic ${ }^{59}$. A recent study suggests that mesoscale ocean-atmosphere coupling markedly affects ocean eddies and the Kuroshio Extension jet through eddy fluxes, with potential effects on large-scale storm tracks ${ }^{63}$. In higher-resolution models, coupling between the ocean and the atmosphere in the extratropics has the potential to influence how climate change affects storms and storm tracks so as to alter our current understanding significantly. 
In the tropics, higher horizontal resolution has been shown to improve the simulation of ENSO in terms of the amplitude, spatial pattern, and teleconnection patterns ${ }^{64}$. More frequent (sub daily) coupling between the atmosphere and ocean also enhances ENSO amplitude ${ }^{65}$. Improvements come from the representation of smallscale Tropical Instability Waves that have an atmospheric imprint that rectifies on both the mean climate and the interannual variability. Projections of increasing frequency of extreme ENSO events ${ }^{66-68}$ are related to shifts in precipitation that may be related to changes in the mean climate ${ }^{69}$. Such mean changes may, in turn, be related to biases in mean SSTs in models ${ }^{70}$. Increasing resolution in coupled models is one way of testing such a hypothesis and improving our understanding of regional climate change in the tropics, including teleconnections. However, a 'reliable' projection of the impact of climate change on ENSO ultimately requires a model with much reduced biases in the mean state and a representation of the ENSO cycle with the correct balance of positive amplifying feedbacks and negative damping feedbacks ${ }^{71}$. This depends not only on the resolved dynamics but also on the interaction with unresolved physical processes such as atmospheric convection.

Conducting multi-decadal simulations with high-resolution models has long been recognised as a challenge. Now the community is on the brink of being able to routinely run coordinated experiments in both atmosphere-only, and crucially, in coupled atmosphere-ocean configurations with a horizontal resolution of $25 \mathrm{~km}$ in the atmosphere and 0.25 degrees in the ocean ${ }^{72,73}$. These HighResMIP experiments will provide a very useful resource for the climate dynamics community, especially the ability to compare dynamical processes at low and high resolutions. The HighResMIP experimental design also attempts to isolate the impact of resolution by running complementary low-resolution experiments without re-tuning the models. While not providing simulations at the resolution at which parameterisation schemes such as those associated with atmospheric convection may be switched off, potentially leading to better simulation of, for instance, summer convective rainfall ${ }^{74,75}$, nor being eddy resolving in the ocean, they nevertheless present a significant improvement when compared to the resolution of the previous generation of climate models. However, high resolution is not a panacea requires careful design and analysis of experiment. Progress may require years, if not decades, of coordinated effort (see section 3.3).

\subsection{Partial Coupling and Pacemaker Experiments}


While atmospheric models forced by SSTs have long provided evidence for the impact of the ocean on the atmosphere, their use in understanding how extratropical SST anomalies influence the extratropical atmosphere is limited. SST-forced experiments produce the wrong sign of SST-heat flux correlations on daily time scales ${ }^{54}$. The development of experiments in which SST anomalies are nudged towards observed SST anomalies in some regions but left free to evolve in others (so-called partial coupling or pacemaker experiments) has proved insightful in understanding the role of the Pacific in the global warming hiatus ${ }^{28,76,77}$. The ocean component need not be dynamical as even mixed-layer partial coupling experiments have shown to be useful in elucidating controls on S. American precipitation ${ }^{55}$. A further type of experiment may prescribe heat-flux convergence anomalies in mixedlayer ocean models to drive ocean-atmosphere heat exchange ${ }^{78,79}$. Pacemaker experiments may also be performed in which the surface winds are nudged towards observed values ${ }^{27,80}$.

While pacemaker experiments are starting to be used more in the study of natural decadal variations in climate ${ }^{81}$ - the background from which the forced climate change signal emerges - they have not been fully exploited in the study of the dynamics of forced climate change. One example could be in the understanding of the north-south asymmetry in the temperature response, described above (section 2.2). Hemispheric differences in radiation balance have been shown to be related to persistent biases in models such as the 'double ITCZ' which may impact projections of regional climate change ${ }^{82,83}$. Pacemaker experiments could be used to artificially correct such biases or to control the level of hemispheric asymmetry in the climate change signal.

Global models with regional coupling may also be employed in understanding future changes in teleconnections arising from natural modes of variability e.g. by specifying observed SSTs in the Pacific associated with ENSO on top of different patterns of mean SST change. The advantages over atmosphere-only simulations would be in simulating the coupled aspects of teleconnections and the advantage over using fully coupled models would be in partially correcting SST biases such as the extended equatorial Pacific cold tongue. Another problem that would be amenable to such an approach would be the role of polar amplification and sea-ice decline in modifying mid-latitude weather (see section 2.1). 
These are just a few examples of where pacemaker experiments could be useful in understanding the dynamics of regional climate change. There are many other possibilities.

\subsection{Complex Diagnostics and Simplified Models}

The profile of metrics is growing within the climate modelling community with efforts to coordinate software and provide portals to calculate metrics for use in model evaluation and climate projections ${ }^{84}$. Basic metrics evaluate emergent aspects of climate such as the spatial distribution of core variables of temperature and precipitation. More process-based metrics, for example, those used to evaluate the strength of different processes/feedbacks in the ENSO cycle ${ }^{51}$, are also now routinely used. The next level of diagnostics should address dynamical aspects of climate. Examples include the use of eddy-mean flow diagnostics, Lagrangian feature tracking and concepts such as moist static energy ${ }^{85}$, the use of Potential Vorticity budgets to asses the trajectories of storms ${ }^{86}$ or assessment of features such as stationary waves ${ }^{87,88}$. Development of more complex dynamical metrics should be encouraged. Also, we need to find ways of using these metrics to better inform the likelihood of projections of future climate change seen in models. This is particularly important in cases where simple emergent constraints ${ }^{89}$ have not been found.

There is no doubt that complex climate models have revolutionized the study of weather and climate. However, models that seek to represent all the complexities of dynamics, physics and, increasingly, biogeochemical cycles are often as difficult to understand as the real world itself. Simplified or 'stripped down' numerical models, known as hierarchies, are growing in use and have been applied in understanding climate dynamics ${ }^{90}$. Examples include dry dynamical atmosphere models with simple Newtonian cooling representing radiation and aquaplanet simulations with more complete moist physical processes, clouds and 'grey' radiation (Fig. 3) 91,92.

Studies of the basic dynamics of planetary atmospheres may provide insight and allow us to develop our theoretical understanding of climate dynamics in the complex Earth. The poleward migration of the eddy-driven on theoretical 'ball bearing' planets (i.e. no mountains, continents or variations in the land-surface) at different rotation rates allows us to understand the basic properties of the governing macroturbulent scales in the planetary atmospheres, which are more difficult to separate under Earth 
conditions ${ }^{93}$. Similarly idealised models have been useful in understanding the response of the storm track to the increase of upper level baroclincity vs. the decrease in lower level baroclincity during climate change ${ }^{94,95}$. The poleward propagation of storms has been shown to be controlled by both the upper-level Potential Vorticity anomaly and by diabatic processes ${ }^{86}$. Both processes which are predicted to be enhanced during global warming, leading to a stronger SW-NE tilt of the storms in the $\mathrm{N}$. hemisphere and an overall poleward shift ${ }^{96}$.

Idealised models are also being used to reshape the understanding of tropical largescale circulations. The classical view of the monsoon as a planetary-scale sea breeze circulation is inadequate. Rather, monsoons can be viewed as the excursions of tropical convergence zones over land ${ }^{97}$. Monsoon onset is usually rapid and not adequately explained by the classical theory. An aquaplanet simulation with a simple mixed-layer ocean has been used to advance our understanding of monsoon onset or the rapid 'jump' in the location of maximum precipitation ${ }^{85}$. Both remotely forced stationary waves and local processes (e.g., latent heating and land-atmosphere interaction) can influence regional monsoon dynamics in terms of timing and strength. A long-standing problem in many climate models is the inability to produce enough precipitation over land in the major monsoon systems. Rainfall may preferentially occur over the ocean, for example in the $\mathrm{S}$. Asian monsoon ${ }^{98}$. While land-surface and SST errors may be important ${ }^{99}$, the coupling between atmospheric convection and the dynamical flow is clearly of leading-order importance in setting the mean rainfall and variability. Under climate change, global monsoon rainfall generally increases but that increase does not scale with global mean temperature change, as there is a compensation between a weakening circulation and increased column water vapour ${ }^{100}$.

\subsection{Discussion - More Dynamics Please}

Whether the goals of the Paris Agreement of "keeping a global temperature rise this century well below 2 degrees Celsius above pre-industrial levels and to pursue efforts to limit the temperature increase even further to 1.5 degrees Celsius" are realised or not, adaptation to climate change is essential. For this we need the best information about future changes in regional climate, much of which is controlled by the dynamical behaviour of the atmosphere, the ocean and their mutual interaction, as well as interaction with other components of the climate system such as the land surface. This understanding can also lead to improved near-term climate predictions. 
The challenge for the climate dynamics community is to produce this information by exploiting hierarchies of models, including the new generation of high-resolution models, by developing metrics to evaluate dynamical processes to explain projections and to design new targeted model experiments to isolate dynamical drivers of change. However, perhaps the biggest challenge is to produce thoeries of regional climate change, on a par with, for example, theories of baroclinic instability, that can be rigorously tested using both observations and models.

This perspective highlights three frontline problems in climate dynamics in which the ocean plays a key role; the response to external forcing of storms, blocks and jet streams, ocean-basin to ocean-basin and tropical-extratropical teleconnections and the development of predictive theories of climate dynamics. Other problems, such as those involving interactions between the troposphere and stratosphere, are also urgent. We have also highlighted some new techniques and capacity in the use of climate models to address these problems. We recommend that the climate dynamics community exploit these opportunities. 




Figure 1: Sea Surface Temperature trends from observations for the period 19792012 indicating the concept of inter-ocean-basin teleconnections. If SSTs are relaxed to observations in the tropical and subtropical Atlantic in a model, the trade winds in the Pacific increase resulting in a subsequent cooling trend there ${ }^{31,32}$. Nevertheless, current coupled climate models tend to underestimate the magnitude of the coupling 41 

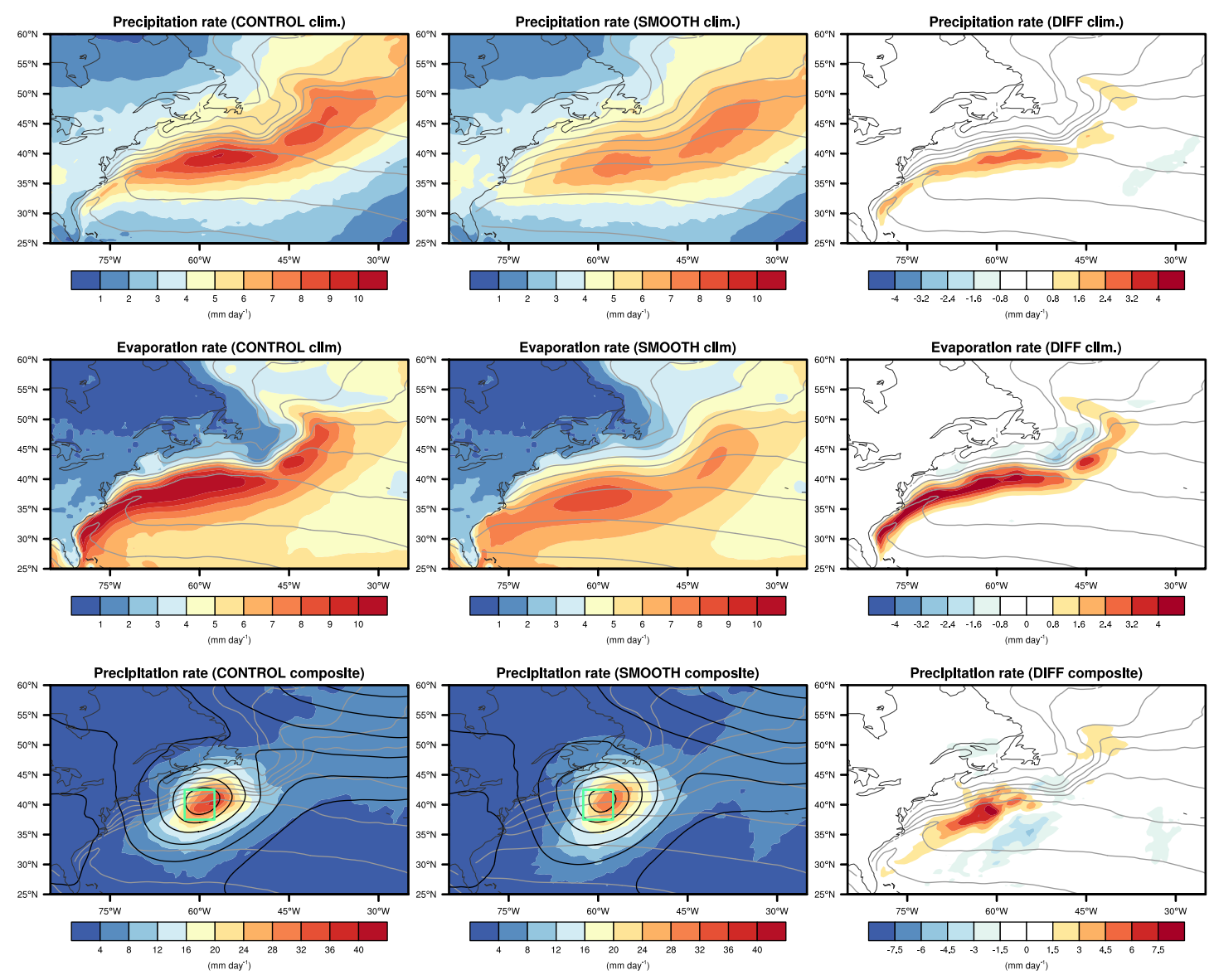

Figure 2: The influence of sharp SST gradients in the Gulf Stream on the hydrological cycle of individual storms and their rectification on the mean climate state. Figures are derived from atmosphere model simulations ${ }^{59}$, performed at $50 \mathrm{~km}$ horizontal resolution, in which the Gulf Stream is represented at equivalent $50 \mathrm{~km}$ resolution (CONTROL) and in which SST gradients are smoothed out (SMOOTH). Upper panels: mean Nov-Mar precipitation in the CONTROL and SMOOTH experiments and their differences. Middle panels: evaporation. Lower panels: Cyclone composites of SLP and precipitation rate. Grey lines on each figure are SST contours. 

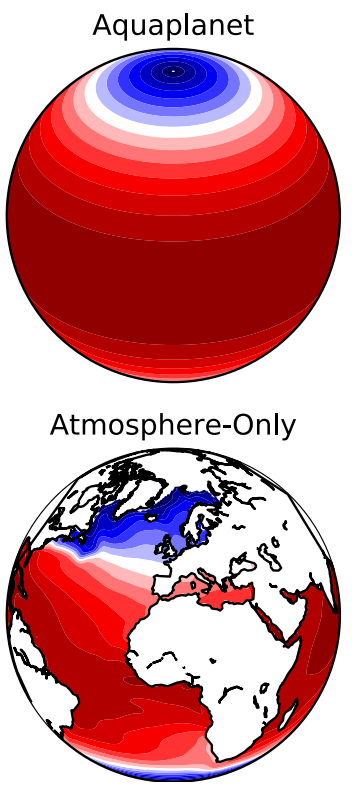

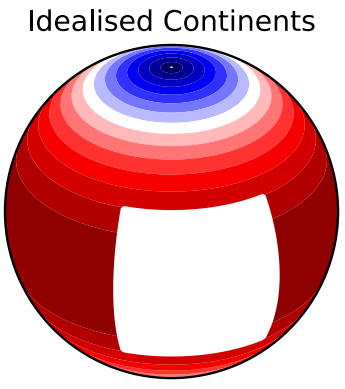

Coupled Atmos-Ocean

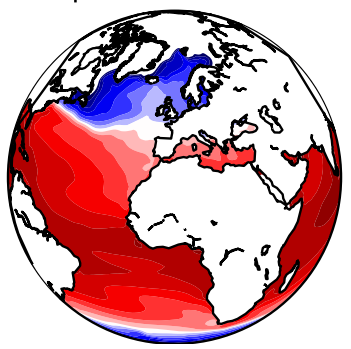

Figure 3: Schematic indicating the concept of the 'hierarchies of models'.

Configurations may range from a simple aquaplanet design with either fixed SSTs or a simple mixed-layer ocean, through simplified continental configurations, atmosphere-only and coupled atmosphere-ocean configurations. Coupling allows for a better representation of how the atmosphere and ocean interact but may also result in biases in models, as can be seen in differences in the SST field in the bottom left (from observations) and bottom right (HadGEM2-AO coupled model).

\subsection{Acknowledgements}

We acknowledge the support of CLIVAR in setting up the Climate Dynamics Panel and their travel support for hosting panel meetings. MC acknowledges support from NERC NE/N018486/1.

\subsection{References}

$1 \quad$ Bjerknes, J. Atlantic air-sea interaction. Advances in Geophysics 20, 1-84 (1964).

2 Bauer, P., Thorpe, A. \& Brunet, G. The quiet revolution of numerical weather prediction. Nature 525, 47-55, doi:10.1038/nature14956 (2015). 
3 Meehl, G. et al. DECADAL CLIMATE PREDICTION An Update from the Trenches. Bulletin of the American Meteorological Society 95, 243-267, doi:10.1175/BAMS-D-12-00241.1 (2014).

$4 \quad$ Andrews, T., Gregory, J., Webb, M. \& Taylor, K. Forcing, feedbacks and climate sensitivity in CMIP5 coupled atmosphere-ocean climate models. Geophysical Research Letters 39, doi:10.1029/2012GL051607 (2012).

5 Feldl, N. \& Bordoni, S. Characterizing the Hadley Circulation Response through Regional Climate Feedbacks. Journal of Climate 29, 613-622, doi:10.1175/JCLI-D-15-0424.1 (2016).

6 Shepherd, T. Atmospheric circulation as a source of uncertainty in climate change projections. Nature Geoscience 7, 703-708, doi:10.1038/NGEO2253 (2014).

7 Deser, C., Phillips, A., Bourdette, V. \& Teng, H. Uncertainty in climate change projections: the role of internal variability. Climate Dynamics 38, 527-546, doi:10.1007/s00382-010-0977-x (2012).

$8 \quad$ Collins, M. et al. in Climate Change 2013: The Physical Science Basis. Contribution of Working Group I to the Fifth Assessment Report of the Intergovernmental Panel on Climate Change (ed T.F. Stocker, D. Qin, G.-K. Plattner, M. Tignor, S.K. Allen, J. Boschung, A. Nauels, Y. Xia, V. Bex and P.M. Midgley) ( Cambridge University Press, 2013).

9 Masato, G., Woollings, T. \& Hoskins, B. Structure and impact of atmospheric blocking over the Euro-Atlantic region in present-day and future simulations. Geophysical Research Letters 41, 1051-1058, doi:10.1002/2013GL058570 (2014).

10 Zhang, X., Zwiers, F., Li, G., Wan, H. \& Cannon, A. Complexity in estimating past and future extreme short-duration rainfall. Nature Geoscience 10, 255-+, doi:10.1038/NGEO2911 (2017).

11 van der Wiel, K. et al. The Resolution Dependence of Contiguous US Precipitation Extremes in Response to CO2 Forcing. Journal of Climate 29, 7991-8012, doi:10.1175/JCLI-D-16-0307.1 (2016).

12 Woollings, T., Gregory, J., Pinto, J., Reyers, M. \& Brayshaw, D. Response of the North Atlantic storm track to climate change shaped by oceanatmosphere coupling. Nature Geoscience 5, 313-317, doi:10.1038/NGEO1438 (2012).

13 Butler, A., Thompson, D. \& Heikes, R. The Steady-State Atmospheric Circulation Response to Climate Change-like Thermal Forcings in a Simple General Circulation Model. Journal of Climate 23, 3474-3496, doi:10.1175/2010JCLI3228.1 (2010).

14 Scaife, A. et al. Climate change projections and stratosphere-troposphere interaction. Climate Dynamics 38, 2089-2097, doi:10.1007/s00382-011-10807 (2012).

15 Manzini, E. et al. Northern winter climate change: Assessment of uncertainty in CMIP5 projections related to stratosphere-troposphere coupling. Journal of Geophysical Research-Atmospheres 119, doi:10.1002/2013JD021403 (2014).

$16 \mathrm{Li}, \mathrm{M}$., Woollings, T., Hodges, K. \& Masato, G. Extratropical cyclones in a warmer, moister climate: A recent Atlantic analogue. Geophysical Research Letters 41, 8594-8601, doi:10.1002/2014GL062186 (2014).

17 Zappa, G., Shaffrey, L. C., Hodges, K. I., Sansom, P. G. \& Stephenson, D. B. A Multimodel Assessment of Future Projections of North Atlantic and European Extratropical Cyclones in the CMIP5 Climate Models*. Journal of Climate 26, 5846-5862, doi:10.1175/JCLI-D-12-00573.1 (2013).

18 de Vries, H., Woollings, T., Anstey, J., Haarsma, R. \& Hazeleger, W. Atmospheric blocking and its relation to jet changes in a future climate. Climate Dynamics 41, 2643-2654, doi:10.1007/s00382-013-1699-7 (2013). 
19 Shaw, T. et al. Storm track processes and the opposing influences of climate change. Nature Geoscience 9, 656-+, doi:10.1038/NGEO2783 (2016).

20 Lehmann, J., Coumou, D., Frieler, K., Eliseev, A. \& Levermann, A. Future changes in extratropical storm tracks and baroclinicity under climate change. Environmental Research Letters 9, doi:10.1088/1748-9326/9/8/084002 (2014).

21 Swart, N., Fyfe, J., Gillett, N. \& Marshall, G. Comparing Trends in the Southern Annular Mode and Surface Westerly Jet. Journal of Climate 28, 8840-8859, doi:10.1175/JCLI-D-15-0334.1 (2015).

22 Barnes, E. \& Screen, J. The impact of Arctic warming on the midlatitude jetstream: Can it? Has it? Will it? Wiley Interdisciplinary Reviews-Climate Change 6, 277-286, doi:10.1002/wcc.337 (2015).

23 Semmler, T. et al. Seasonal Atmospheric Responses to Reduced Arctic Sea Ice in an Ensemble of Coupled Model Simulations. Journal of Climate 29, 5893-5913, doi:10.1175/JCLI-D-15-0586.1 (2016).

24 Barnes, E. \& Polvani, L. CMIP5 Projections of Arctic Amplification, of the North American/North Atlantic Circulation, and of Their Relationship. Journal of Climate 28, 5254-5271, doi:10.1175/JCLI-D-14-00589.1 (2015).

25 Deser, C., Tomas, R. \& Sun, L. The Role of Ocean-Atmosphere Coupling in the Zonal-Mean Atmospheric Response to Arctic Sea Ice Loss. Journal of Climate 28, 2168-2186, doi:10.1175/JCLI-D-14-00325.1 (2015).

26 Francis, J. \& Vavrus, S. Evidence linking Arctic amplification to extreme weather in mid-latitudes. Geophysical Research Letters 39, doi:10.1029/2012GL051000 (2012).

27 England, M. et al. Recent intensification of wind-driven circulation in the Pacific and the ongoing warming hiatus. Nature Climate Change 4, 222-227, doi:10.1038/NCLIMATE2106 (2014).

28 Kosaka, Y. \& Xie, S. Recent global-warming hiatus tied to equatorial Pacific surface cooling. Nature 501, 403-+, doi:10.1038/nature12534 (2013).

29 Meehl, G. A., Hu, A., Arblaster, J., Fasullo, J. \& Trenberth, K. E. Externally forced and internally generated decadal climate variability associated with the Interdecadal Pacific Oscillation. Journal of Climate, doi:10.1175/JCLI-D-1200548.1 (2013).

30 Kucharski, F., Kang, I., Farneti, R. \& Feudale, L. Tropical Pacific response to 20th century Atlantic warming. Geophysical Research Letters 38, doi:10.1029/2010GL046248 (2011).

$31 \mathrm{Li}, \mathrm{X} ., \mathrm{Xie}, \mathrm{S}$., Gille, S. \& Yoo, C. Atlantic-induced pan-tropical climate change over the past three decades. Nature Climate Change 6, 275-+, doi:10.1038/NCLIMATE2840 (2016).

32 McGregor, S. et al. Recent Walker circulation strengthening and Pacific cooling amplified by Atlantic warming. Nature Climate Change 4, 888-892, doi:10.1038/NCLIMATE2330 (2014).

33 Han, W. et al. Intensification of decadal and multi-decadal sea level variability in the western tropical Pacific during recent decades. Climate Dynamics 43, 1357-1379, doi:10.1007/s00382-013-1951-1 (2014).

34 Booth, B., Dunstone, N., Halloran, P., Andrews, T. \& Bellouin, N. Aerosols implicated as a prime driver of twentieth-century North Atlantic climate variability (vol 484, pg 228, 2012). Nature 485, 534-534, doi:10.1038/nature11138 (2012).

35 Clement, A. et al. The Atlantic Multidecadal Oscillation without a role for ocean circulation. Science 350, 320-+, doi:10.1126/science.aab3980 (2015).

36 Zhang, R. et al. Have Aerosols Caused the Observed Atlantic Multidecadal Variability? Journal of the Atmospheric Sciences 70, 1135-1144, doi:10.1175/JAS-D-12-0331.1 (2013).

37 Zhang, R. et al. Comment on "The Atlantic Multidecadal Oscillation without a role for ocean circulation". Science 352, doi:10.1126/science.aaf1660 (2016). 
38 Gulev, S., Latif, M., Keenlyside, N., Park, W. \& Koltermann, K. North Atlantic Ocean control on surface heat flux on multidecadal timescales. Nature 499, 464-+, doi:10.1038/nature12268 (2013).

$39 \mathrm{Li}, \mathrm{C} .$, Stevens, B. \& Marotzke, J. Eurasian winter cooling in the warming hiatus of 1998-2012. Geophysical Research Letters 42, 8131-8139, doi:10.1002/2015GL065327 (2015).

40 Deser, C., Guo, R. \& Lehner, F. The relative contributions of tropical Pacific sea surface temperatures and atmospheric internal variability to the recent global warming hiatus. Geophysical Research Letters 44, 7945-7954, doi:10.1002/2017GL074273 (2017).

41 Kajtar, J. B., Santoso, A., McGregor, S., England, M. \& Baillie, Z. Model under-representation of decadal Pacific trade wind trends and its link to tropical Atlantic bias. Climate Dynamics, doi:doi:10.1007/s00382-017-3699-5 (2017).

42 Holland, P. \& Kwok, R. Wind-driven trends in Antarctic sea-ice drift. Nature Geoscience 5, 872-875, doi:10.1038/NGEO1627 (2012).

43 Simpkins, G., McGregor, S., Taschetto, A., Ciasto, L. \& England, M. Tropical Connections to Climatic Change in the Extratropical Southern Hemisphere: The Role of Atlantic SST Trends. Journal of Climate 27, 4923-4936, doi:10.1175/JCLI-D-13-00615.1 (2014).

44 Purich, A. et al. Tropical Pacific SST Drivers of Recent Antarctic Sea Ice Trends. Journal of Climate 29, 8931-8948, doi:10.1175/JCLI-D-16-0440.1 (2016).

$45 \mathrm{Li}, \mathrm{X}$., Holland, D., Gerber, E. \& Yoo, C. Impacts of the north and tropical Atlantic Ocean on the Antarctic Peninsula and sea ice. Nature 505, 538-+, doi:10.1038/nature12945 (2014).

46 Talento, S. \& Barriero, M. Control of the South Atlantic Convergence Zone by extratropical thermal forcing. Climate Dynamics, doi:DOI 10.1007/s00382017-3647-4 (2017).

47 Hwang, Y.-T., Xie, S.-P., Deser, C. \& Kang, S., M. Connecting tropical climate change with Southern Ocean heat uptake. Geophysical Research Letters, doi: doi:10.1002/2017GL074972 (2017).

48 Roemmich, D. et al. Unabated planetary warming and its ocean structure since 2006. Nature Climate Change 5, 240-245, doi:10.1038/NCLIMATE2513 (2015).

49 Bodas-Salcedo, A. et al. Large Contribution of Supercooled Liquid Clouds to the Solar Radiation Budget of the Southern Ocean. Journal of Climate 29, 4213-4228, doi:10.1175/JCLI-D-15-0564.1 (2016).

50 Hawcroft, M. et al. Southern Ocean albedo, inter-hemispheric energy transports and the double ITCZ: global impacts of biases in a coupled model. Climate Dynamics 48, 2279-2295, doi:10.1007/s00382-016-3205-5 (2017).

51 Jin, F., Kim, S. \& Bejarano, L. A coupled-stability index for ENSO. Geophysical Research Letters 33, doi:10.1029/2006GL027221 (2006).

52 Dommenget, D. \& Latif, M. A cautionary note on the interpretation of EOFs. Journal of Climate 15, 216-225, doi:10.1175/15200442(2002)015<0216:ACNOTI>2.0.CO;2 (2002).

53 Monahan, A., Fyfe, J., Ambaum, M., Stephenson, D. \& North, G. Empirical Orthogonal Functions: The Medium is the Message. Journal of Climate 22, 6501-6514, doi:10.1175/2009JCLI3062.1 (2009).

54 Barsugli, J. \& Battisti, D. The basic effects of atmosphere-ocean thermal coupling on midlatitude variability. Journal of the Atmospheric Sciences 55, 477-493, doi:10.1175/1520-0469(1998)055<0477:TBEOAO>2.0.CO;2 (1998).

55 Barreiro, M. Influence of ENSO and the South Atlantic Ocean on climate predictability over Southeastern South America. Climate Dynamics 35, 14931508, doi:10.1007/s00382-009-0666-9 (2010). 
56 Minobe, S., Kuwano-Yoshida, A., Komori, N., Xie, S. \& Small, R. Influence of the Gulf Stream on the troposphere. Nature 452, 206-U251, doi:10.1038/nature06690 (2008).

57 Nakamura, H., Sampe, T., Tanimoto, Y. \& Shimpo, A. in Earth's Climate: The atmosphere-ocean interaction. (eds C Wang, S-P Xie, \& J A Carton) (American Geophysical Union, 2004).

$58 \mathrm{Ma}, \mathrm{X}$. et al. Western boundary currents regulated by interaction between ocean eddies and the atmosphere. Nature 535, 533-+, doi:10.1038/nature18640 (2016).

59 O'Reilly, C. H., Minobe, S. \& Kuwano-Yoshida, A. The influence of the Gulf Stream on wintertime European blocking. Climate Dynamics (2016).

60 O'Reilly, C. H., Minobe, S., Kuwano-Yoshida, A. \& Woollings, T. The Gulf Stream influence on wintertime North Atlantic jet variability. Quarterly Journal of the Royal Meteorological Society (2016).

61 Pfahl, S., Schwierz, C., Croci-Maspoli, M., Grams, C. \& Wernli, H. Importance of latent heat release in ascending air streams for atmospheric blocking.

Nature Geoscience 8, 610-+, doi:10.1038/NGEO2487 (2015).

62 Kuwano-Yoshida, A. \& Minobe, S. Storm-Track Response to SST Fronts in the Northwestern Pacific Region in an AGCM. Journal of Climate 30, 10811102, doi:10.1175/JCLI-D-16-0331.1 (2017).

$63 \mathrm{Ma}, \mathrm{X}$. et al. Winter Extreme Flux Events in the Kuroshio and Gulf Stream Extension Regions and Relationship with Modes of North Pacific and Atlantic Variability. Journal of Climate 28, 4950-4970, doi:10.1175/JCLI-D-14-00642.1 (2015).

64 Shaffrey, L. et al. UK HiGEM: The New UK High-Resolution Global Environment Model-Model Description and Basic Evaluation. Journal of Climate 22, 1861-1896, doi:10.1175/2008JCLI2508.1 (2009).

65 Masson, S. et al. Impact of intra-daily SST variability on ENSO characteristics in a coupled model. Climate Dynamics 39, 681-707, doi:10.1007/s00382-0111247-2 (2012).

66 Cai, W. et al. Increasing frequency of extreme El Nino events due to greenhouse warming. Nature Climate Change 4, 111-116, doi:10.1038/NCLIMATE2100 (2014).

67 Cai, W. et al. Increased frequency of extreme La Nina events under greenhouse warming. Nature Climate Change 5, 132-137, doi:10.1038/NCLIMATE2492 (2015).

68 Latif, M., Semenov, V. \& Park, W. Super El Ninos in response to global warming in a climate model. Climatic Change 132, 489-500, doi:10.1007/s10584-015-1439-6 (2015).

69 Power, S., Delage, F., Chung, C., Kociuba, G. \& Keay, K. Robust twenty-firstcentury projections of El Nino and related precipitation variability. Nature 502, 541-+, doi:10.1038/nature12580 (2013).

70 Xie, S.-P. et al. Towards predictive understanding of regional climate change. Nature Climate Change 5, 921-930, doi:10.1038/NCLIMATE2689 (2015).

71 Ferrett, S., Collins, M. \& Ren, H.-L. Understanding Bias in the Evaporative Damping of El Nino-Southern Oscillation Events in CMIP5 Models. Journal of Climate 30, 6351-6370, doi:10.1175/JCLI-D-16-0748.1 (2017).

72 Small, R. et al. A new synoptic scale resolving global climate simulation using the Community Earth System Model. Journal of Advances in Modeling Earth Systems 6, 1065-1094, doi:10.1002/2014MS000363 (2014).

73 Haarsma, R. et al. High Resolution Model Intercomparison Project (HighResMIP v1.0) for CMIP6. Geoscientific Model Development 9, 41854208, doi:10.5194/gmd-9-4185-2016 (2016). 
74 Kendon, E. et al. Heavier summer downpours with climate change revealed by weather forecast resolution model. Nature Climate Change 4, 570-576, doi:10.1038/NCLIMATE2258 (2014).

75 Brisson, E. et al. How well can a convection-permitting climate model reproduce decadal statistics of precipitation, temperature and cloud characteristics? Climate Dynamics 47, 3043-3061, doi:10.1007/s00382-0163012-z (2016).

76 Alexander, M. et al. The atmospheric bridge: The influence of ENSO teleconnections on air-sea interaction over the global oceans. Journal of Climate 15, 2205-2231, doi:10.1175/15200442(2002)015<2205:TABTIO>2.0.CO;2 (2002).

77 Chikamoto, Y. et al. Skilful multi-year predictions of tropical trans-basin climate variability. Nature Communications 6, doi:10.1038/ncomms7869 (2015).

78 Sutton, R. \& Mathieu, P. Response of the atmosphere-ocean mixed-layer system to anomalous ocean heat-flux convergence. Quarterly Journal of the Royal Meteorological Society 128, 1259-1275, doi:10.1256/003590002320373283 (2002).

79 Kwon, Y., Deser, C. \& Cassou, C. Coupled atmosphere-mixed layer ocean response to ocean heat flux convergence along the Kuroshio Current Extension. Climate Dynamics 36, 2295-2312, doi:10.1007/s00382-010-07648 (2011).

80 Ding, H. et al. The variability of the East Asian summer monsoon and its relationship to ENSO in a partially coupled climate model. Climate Dynamics 42, 367-379, doi:10.1007/s00382-012-1642-3 (2014).

81 Boer, G. et al. The Decadal Climate Prediction Project (DCPP) contribution to CMIP6. Geoscientific Model Development 9, 3751-3777, doi:10.5194/gmd-93751-2016 (2016).

82 Frierson, D. \& Hwang, Y. Extratropical Influence on ITCZ Shifts in Slab Ocean Simulations of Global Warming. Journal of Climate 25, 720-733, doi:10.1175/JCLI-D-11-00116.1 (2012).

83 Haywood, J. et al. The impact of equilibrating hemispheric albedos on tropical performance in the HadGEM2-ES coupled climate model. Geophysical Research Letters 43, 395-403, doi:10.1002/2015GL066903 (2016).

84 Gleckler, P. et al. A more powerful reality test for climate models. EOS 97 , doi:doi:10.1029/2016EO051663 (2016).

85 Bordoni, S. \& Schneider, T. Monsoons as eddy-mediated regime transitions of the tropical overturning circulation. Nature Geoscience 1, 515-519, doi:10.1038/ngeo248 (2008).

86 Tamarin, T. \& Kaspi, Y. The Poleward Motion of Extratropical Cyclones from a Potential Vorticity Tendency Analysis. Journal of the Atmospheric Sciences 73, 1687-1707, doi:10.1175/JAS-D-15-0168.1 (2016).

87 Simpson, I., Seager, R., Ting, M. \& Shaw, T. Causes of change in Northern Hemisphere winter meridional winds and regional hydroclimate. Nature Climate Change 6, 65-70, doi:10.1038/NCLIMATE2783 (2016).

88 Kaspi, Y. \& Schneider, T. Winter cold of eastern continental boundaries induced by warm ocean waters. Nature 471, 621-+, doi:10.1038/nature09924 (2011).

89 Collins, M. et al. Quantifying future climate change. Nature Climate Change 2, 403-409, doi:10.1038/nclimate1414 (2012).

90 Farneti, R. \& Vallis, G. Meridional Energy Transport in the Coupled Atmosphere-Ocean System: Compensation and Partitioning. Journal of Climate 26, 7151-7166, doi:10.1175/JCLI-D-12-00133.1 (2013).

91 HELD, I. \& SUAREZ, M. A PROPOSAL FOR THE INTERCOMPARISON OF THE DYNAMICAL CORES OF ATMOSPHERIC GENERAL-CIRCULATION 
MODELS. Bulletin of the American Meteorological Society 75, 1825-1830, doi:10.1175/1520-0477(1994)075<1825:APFTIO>2.0.CO;2 (1994).

92 Frierson, D., Held, I. \& Zurita-Gotor, P. A gray-radiation aquaplanet moist GCM. Part I: Static stability and eddy scale. Journal of the Atmospheric Sciences 63, 2548-2566, doi:10.1175/JAS3753.1 (2006).

93 Chemke, R. \& Kaspi, Y. Poleward migration of eddy-driven jets. Journal of Advances in Modeling Earth Systems 7, 1457-1471, doi:10.1002/2015MS000481 (2015).

94 Yuval, J. \& Kaspi, Y. The Effect of Vertical Baroclinicity Concentration on Atmospheric Macroturbulence Scaling Relations. Journal of the Atmospheric Sciences 74, 1651-1667, doi:10.1175/JAS-D-16-0277.1 (2017).

95 Yuval, J. \& Kaspi, Y. Eddy Activity Sensitivity to Changes in the Vertical Structure of Baroclinicity. Journal of the Atmospheric Sciences 73, 1709-1726, doi:10.1175/JAS-D-15-0128.1 (2016).

96 Tamarin, T. \& Kaspi, Y. Enhanced poleward propagation of storms under climate change. Nature Geoscience, doi:DOI: 10.1038/s41561-017-0001-8 (2017).

97 Walker, J., Bordoni, S. \& Schneider, T. Interannual Variability in the LargeScale Dynamics of the South Asian Summer Monsoon. Journal of Climate 28, 3731-3750, doi:10.1175/JCLI-D-14-00612.1 (2015).

98 Sperber, K. et al. The Asian summer monsoon: an intercomparison of CMIP5 vs. CMIP3 simulations of the late 20th century. Climate Dynamics 41, 27112744, doi:10.1007/s00382-012-1607-6 (2013).

99 Levine, R., Turner, A., Marathayil, D. \& Martin, G. The role of northern Arabian Sea surface temperature biases in CMIP5 model simulations and future projections of Indian summer monsoon rainfall. Climate Dynamics 41, 155-172, doi:10.1007/s00382-012-1656-x (2013).

100 Held, I. \& Soden, B. Robust responses of the hydrological cycle to global warming. Journal of Climate 19, 5686-5699, doi:10.1175/JCLI3990.1 (2006). 